\title{
Induced and noninduced patterns of drinking by food-deprived rats
}

\author{
J. D. KEEHN and EMOKE JOZSVAI \\ York University, Downsview, Ontario, Canada
}

\begin{abstract}
The patterns of drinking by 3 food-deprived rats were observed in 40 experimental sessions in which food reinforcement was scheduled at fixed intervals of $4 \mathrm{~min}$ (FI-4) and $1 \mathrm{~min}$ (FI-1) for 20 sessions each. Under the FI-1 schedule, water intake increased in amount over the 20 sessions, and induced drinking became stereotyped in frequency, magnitude, and latency within and between sessions. Under the FI-4 schedule, drinks occurred infrequently, with long and variable latencies and magnitudes, and water intake did not increase with training. We concluded that, under the FI-4 schedule, drinking was normal, not induced, and that the fluid intake responsible for the well-known bitonic relationship between interreinforcement interval and water consumption represents different proportions of induced and noninduced drinks at different intervals.
\end{abstract}

One of the best documented beliefs about scheduleinduced polydipsia (adjunctive drinking) is that it relates bitonically with interpellet interval (Bond, 1972; Falk, 1966; Flory, 1971; Hawkins, Schrot, Githens, \& Everett, 1972; Keehn \& Colotla, 1971; Roper, 1980; Rosellini \& Burdette, 1980). At intervals in the 1- to 2-min range, adjunctive drinking is maximal; at intervals below $15 \mathrm{sec}$ and above $4 \mathrm{~min}$, only small amounts of drinking normally occur. Reid and Staddon (1982) account for this bitonic relation as follows: " As food rate increases, foodrelated activities and drinking increase together; but at very high food rates food-related activities continue to increase, but drinking rate decreases." (p. 16)

At very high food rates, under continuous reinforcement, for instance, any drinking that occurs is not schedule-induced because there is no intermittency in the schedule. Thus, applied to the bitonic curve, Reid and Staddon's (1982) account assumes that induced and noninduced drinking belong in the same response class. This cannot be true because different eliciting and reinforcing stimuli apply in the two cases. Schedule-induced drinking is nonhomeostatic (Kissileff, 1973), it is not under hydrational control (Kenny, Wright, \& Reynolds, 1976), and it does not involve histaminic factors that accompany food-associated drinking (Kraly, Coogan, Mashkuri, \& Kellman, 1985). Thus, just as the word "water" belongs in different response classes according to whether it is emitted as a mand or a tact (Skinner, 1957), so the act of drinking belongs in different classes when it is induced

This research was supported by a scholarship from the National Science and Engineering Research Council of Canada to Emoke Jozsvai and supplementary minor research grants from Atkinson College, York University. We are grateful to Kirk Shorting for help with the data collection and to Alexander Marr for help with the computer program. The authors' mailing address is Atkinson College, York University, Downsview, Ontario M3J 1P3, Canada. and when it is not schedule-induced. The bitonic relationship between water intake and interpellet interval would be confounded if drinking changed in class across the range of interpellet intervals.

The experimental problem is to differentiate the two kinds of drinking. A way to do this is to compare patterns of induced and noninduced drinking (Keehn, 1984). Schedule-induced drinking is stereotyped in frequency, latency, and duration; whereas, noninduced drinking is unpredictable (Keehn \& Stoyanov, 1986). Keehn and Stoyanov (1986) compared patterns of drinking at two points on the rising portion of the bitonic curve; the present study compares patterns of drinking at two points on the falling portion of the curve, 1-min versus 4-min interpellet intervals.

\section{METHOD}

\section{Subjects}

Four male Sprague-Dawley white rats (supplied by the Charles River Co., Quebec) were used. They were received in the laboratory at about 60 days of age and maintained in individual home cages with free access to food and water for $\mathbf{3 0}$ days, during which they were handled and weighed daily. After that, they were reduced to $85 \%$ of their freefeeding weights by limited rations over several days. At the start of the experiment, the weights of the respective subjects were $355 \mathrm{~g}$ (M9), $317 \mathrm{~g}$ (M10), $354 \mathrm{~g}$ (M11), and $373 \mathrm{~g}$ (M12).
Apparatus
Four standard 2-bar Grason-Stadler rat boxes were modified by the removal of one bar and were fitted with graduated glass water bottles on the outside of each door. The metal spouts of the bottles were $5 \mathrm{~mm}$ in diameter and were angled into the chamber through a hole $5 \mathrm{~cm}$ above floor level such that the bottom of the spout was $2 \mathrm{~mm}$ inside the cham- ber and $16 \mathrm{~cm}$ from the food magazine. The response bar was situated above and to the left of a food magazine that presented 45-mg standard Noyes rat pellets when scheduled. Experimental sessions with each animal always occurred at the same time of day, and each animal al- ways was trained in the same experimental chamber with the same water spout. Spout contacts were routed via Grason-Stadler drinkometers to a Microcomputer Control System (Micro Interfaces) that also controlled the scheduling of reinforcers and sessional data printouts. The cham- 

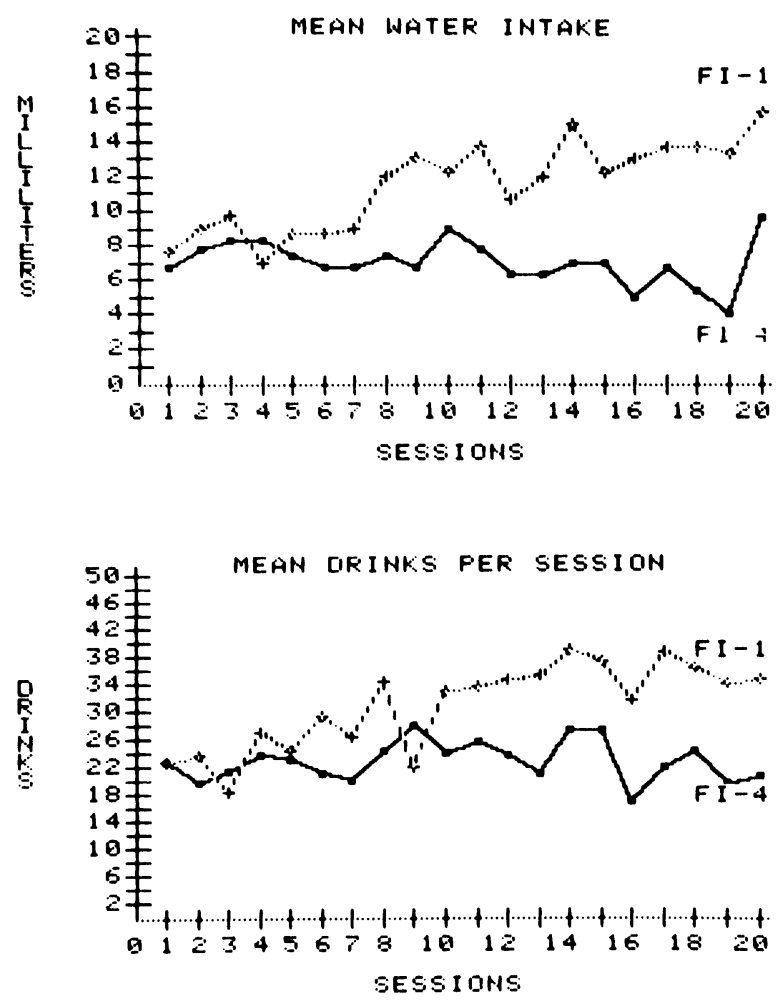

Figure 1. Upper: Mean water intake per session for 3 rats under food-reinforcement schedules with fixed intervals of 1 min (FI-1) and $4 \mathrm{~min}$ (FI-4). Lower: Mean frequency of drinks (maximum 50) per session corresponding to the above water intakes.
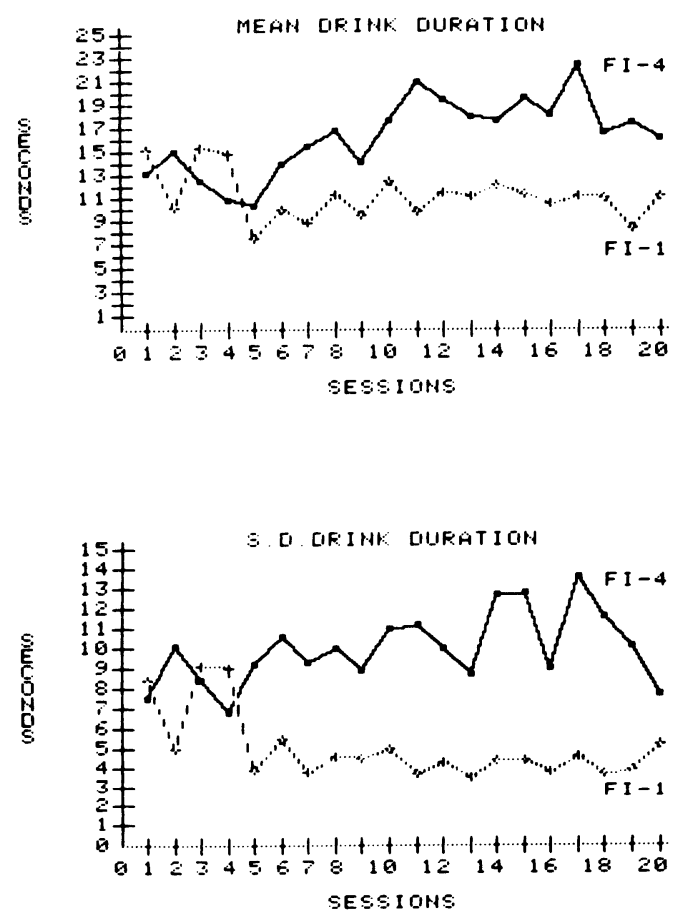

bers were mounted in chests with ventilating fans to mask extraneous noises.

\section{Procedure}

After preliminary adaptation and barpress training with successive approximations, the subjects were maintained for 5 sessions under a continuous reinforcement schedule in which every barpress was reinforced. Sessions terminated when an animal had secured 50 reinforcers. Following this, there were 2 sessions each in which reinforcers were scheduled at fixed intervals of $1 \mathrm{~min}$ (FI-1) and $2 \mathrm{~min}$ (FI-2), respectively. Immediately after these preliminaries, 20 sessions were conducted under a FI-4 schedule, followed directly by 20 sessions with a FI- 1 schedule of reinforcement. Animal M10 died after 11 sessions on this schedule.

Experimental sessions were conducted on 5 days each week, and each lasted until an animal secured 50 reinforcers. After each session the computer printed out the number of reinforcers followed by drinking (frequency), means and standard deviations of latencies of the first lick after reinforcement, and means and standard deviations of drink durations (magnitude) whenever drinks occurred. Because rats drink in bursts of licks several seconds in duration (Stellar \& Hill, 1952), for the purpose of measuring drink duration the computer was programmed to identify a lick bout as any sequence of drinking-tube contacts at least $3 \mathrm{sec}$ long and separated from adjacent-tube contacts by $5 \mathrm{sec}$ or more. This restriction prevented occasional tube contacts by nosing, biting, or pawing from registering as drinks. Genuine drinks less than $3 \mathrm{sec}$ in duration were thus excluded from the data, but, because drinks this short are rare in rats, we judge this loss to be more than offset by the elimination of spurious contacts with the water spout.

Session water intakes were measured in situ from graduations on the water bottles.

\section{RESULTS}

The upper and lower graphs in Figure 1 show, respectively, session-by-session mean water intake (in milliliters)
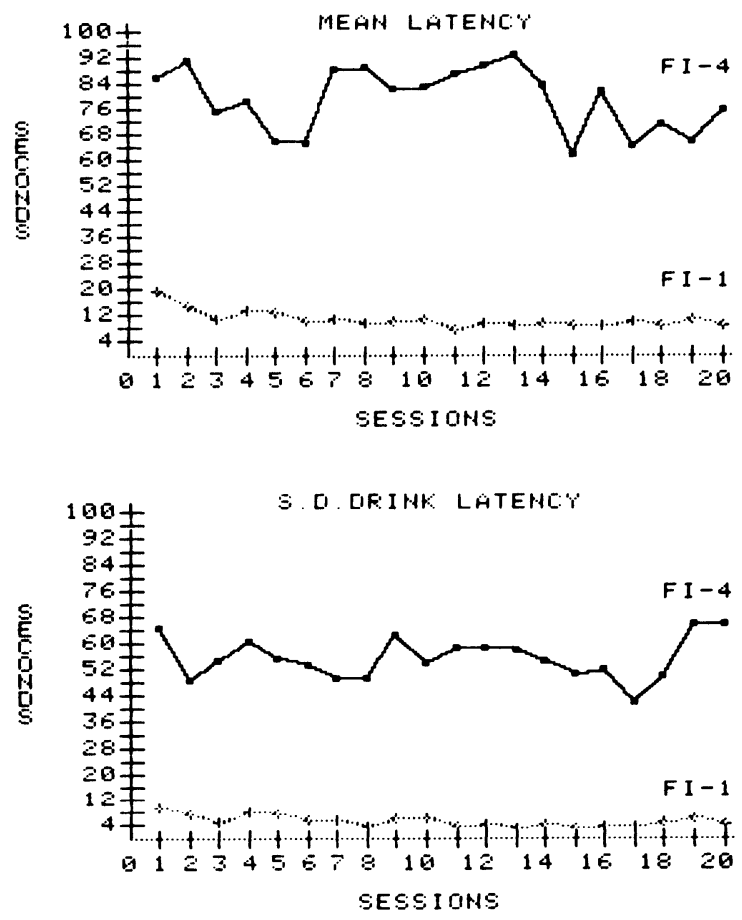

Figure 2. Upper left: Mean durations of drink bouts per session for 3 rats under food-reinforcement schedules with fixed intervals of $1 \mathrm{~min}$ (FI-1) and $4 \mathrm{~min}$ (FI-4). Lower left: Standard deviations of the above drink durations. Upper right: Mean eat -drink latencies per session for 3 rats under FI-1 and FI-4 food-reinforcement schedules. Lower right: Standard deviations of the above latencies. 
and number of interpellet intervals in which drinking occurred (frequency) for the 3 animals (M9, M11, M12) that completed the experiment. At first, the animals drank comparable amounts of water under the two foodreinforcement schedules, but, over sessions, both the intake and the frequency curves diverged such that more drinking occurred under the FI-1 schedule than did under the FI-4 schedule.

Figure 2 shows means and standard deviations of the latencies and durations of the drinks depicted in Figure 1. For drink durations, means and standard deviations were both comparable in early sessions under the two reinforcement schedules, but, over sessions, the curves diverged such that, although the frequency of drinks was lower (Figure 1), the means and standard deviations of the magnitude of these drinks were greater under the FI-4 schedule than they were under the FI- 1 schedule. At the same time, drink latencies under the FI-1 schedule were consistently short, while those under the FI-4 schedule fluctuated both within and between sessions. Thus, with exposure to the two reinforcement schedules, the animals' licking patterns became stereotyped in frequency, latency, and duration with the FI-1, but not with the FI-4, schedule. The two reinforcement schedules did not simply generate different amounts of water intake, they generated different patterns of water consumption.

\section{DISCUSSION}

The fact that drinking at high rates of feeding (e.g., with continuous reinforcement, Keehn \& Stoyanov, 1986) and low rates of feeding (e.g., with 4-min interpellet intervals) occurs erratically in frequency, magnitude, and latency, in comparison with stereotyped schedule-induced drinking, suggests that drinking under high and low rates of feeding belongs in a class of noninduced, rather than induced, drinking. If this is so, then the familiar bitonic relationship between water intake and interreinforcement interval represents a function relating induced extraordinary drinking to interreinforcement time over part of its range, outside of which it is not extraordinary, but ordinary, drinking that occurs. The bitonic curve, therefore, represents the proportion of each class of drinking that occurs at each interreinforcement interval.

\section{REFERENCES}

BoND, N. (1972). Schedule-induced polydipsia as a function of the consummatory rate. The Psychological Record, 23, 377-382.

FALK, J. L. (1966). Schedule-induced polydipsia as a function of fixedinterval length. Journal of the Experimental Analysis of Behavior, 9. 37-39.

Flory, R. (1971). The control of schedule-induced polydipsia: Frequency and magnitude of reinforcement. Learning \& Motivation, 2 215-227.

Hawkins, T. D., Schrot, J. F., Githens, S. H., \& Everett, P. B. (1972). Schedule-induced polydipsia: An analysis of water and alcohol ingestion. In R. M. Gilbert \& J. D. Keehn (Eds.), Schedule effects: Drugs, drinking and aggression (pp. 95-128). Toronto: University of Toronto Press.

KeEHN, J. D. (1984). A control for comparing schedule-induced drinking with other adjunctive behaviors. Bulletin of the Psychonomic Society, 22, 61-62.

Keehn, J. D., \& Colotla, V. A. (1971). Schedule-induced drinking as a function of interpellet interval. Psychonomic Science, 23, 69-71.

Keehn, J. D., \& Stoyanov, E. (1986). The development of adjunctive drinking by rats: Conditioned and unconditioned components. Animal Learning \& Behavior, 14, 411-415.

Kenny, J. R., Wright, J. W., \& Reynolds, T. J. (1976). Scheduleinduced polydipsia: The role of oral and plasma factors. Physiology \& Behavior, 17, 939-945.

KissilefF, H. R. (1973). Nonhomeostatic controls of drinking. In A. N. Epstein, H. R. Kissileff, \& E. Stellar (Eds.), The neurophysiology of thirst: New findings and advances in concepts (pp. 163-198). Washington, DC: Winston.

Kraly, F. S., Coogan, L. A., Mashkuri, P. L., \& Kellman, S. A. (1985). Histamine plays no part in schedule-induced polydipsia in the rat. Physiology \& Behavior, 34, 831-834.

ReID, A. K., \& STADDON, J. E. R. (1982). Schedule-induced drinking: Elicitation, anticipation or behavioral interaction? Journal of the Experimental Analysis of Behavior, 38, 1-18.

ROPER, T. J. (1980). Changes in rate of schedule-induced behaviour in rats as a function of fixed-interval schedule. Quarterly Journal of Experimental Psychology, 32, 159-170.

Rosellini, R. A., \& BurdetTe, D. R. (1980). Meal size and intermeal interval both regulate schedule-induced water intake by rats. Animal Learning \& Behavior, 8, 647-652.

SkInNER, B. F. (1957). Verbal Behavior. New York: Appleton Century. STEllar, E., \& Hill, J. H. (1952). The rat's rate of drinking as a function of water deprivation. Journal of Comparative \& Physiological Psychology, 45, 96-102.

(Manuscript received July 21, 1988.) 